\title{
Emerging Treatments for Non-infectious Uveitis
}

\author{
Alay S Banker, ${ }^{1}$ Carlos Pavesio, ${ }^{2}$ and Pauline Merrill ${ }^{3}$ \\ 1. Banker's Retina Clinic and Laser Centre, Gujarat, India; 2. Moorfields Eye Hospital, London, UK; 3. Rush University Medical Center, Chicago, IL, US
}

$\mathrm{T}$ he primary goals of treatment in patients with non-infectious uveitis (NIU) are to control ocular inflammation and prevent sight-threatening complications such as macular edema and glaucoma. Systemic corticosteroids are the mainstay of treatment in NIU of the posterior segment (NIU-PS); however, long-term use is associated with treatment-limiting adverse effects. The need for agents with improved safety and tolerability coupled with recent insights into the pathogenesis of NIU-PS have led to the development of novel targeted interventions that potentially reduce or eliminate systemic corticosteroid exposure. Targeted interventions include intraocular drug delivery systems that provide high local concentrations at the site of inflammation with low systemic exposure and therapeutic agents, such as monoclonal antibodies that target specific pro-inflammatory cytokines and cytokine-mediated signaling pathways. The expanding range of therapeutic options enhances the ability to tailor therapy according to individual patient circumstances and optimize outcomes in patients with NIU-PS.

\section{Keywords}

Clinical trial, corticosteroid, cytokines, disease management, immunosuppressive agent, intraocular injection, intravitreal, monoclonal antibody, intravitreal, uveitis

Disclosure: Alay S Banker is a consultant for Santen, Inc. Carlos Pavesio has received personal fees from Alimera, Allergan, Kowa, Novartis and Santen. Pauline Merrill has received grants from Abbvie, Clearside, Eyegate and Santen and personal fees from Abbvie Allergan, pSividia and Santen.

Acknowledgments: Editorial assistance was provided by Alexander Simon and Kenneth Glasscock of Bioscience Communications (New York, NY, US) and funded by Santen, Inc.

Review Process: Double-blind peer review.

Compliance with Ethics: This study involves a review of the literature and did not involve any studies with human or animal subjects performed by any of the authors.

Authorship: The named author meets the Internationa Committee of Medical Journal Editors (ICMJE) criteria for authorship of this manuscript, takes responsibility for the integrity of the work as a whole, and has given final approval for the version to be published.

Open Access: This article is published under the Creative Commons Attribution Non-commercial License, which permits any non-commercial use, distribution, adaptation, and reproduction provided the original author and source are given appropriate credit. (c) The Authors 2018.

Received: July 26, 2018

Accepted: October 4, 2018

Citation: US Ophthalmic Review. 2018;11(2):81-6

Corresponding Author: Alay S Banker, Banker's Retina Clinic and Laser Centre, 5 Subhash Society, Behind Ishvar Bhuvan, Navrangpura, Ahmedabad Gujarat, India 380009. E: alay.banker@gmail.com

Support: The publication of this article was supported by Santen, Inc
Uveitis comprises a range of intraocular inflammatory conditions of both infectious and non-infectious origin that can result in irreversible ocular damage and impaired vision or blindness. ${ }^{1}$ Effective management is therefore vitally important to prevent ocular damage and preserve visual acuity and quality of life. ${ }^{1-3}$

Therapeutic management of uveitis is dictated by etiology and anatomic location. ${ }^{1}$ Infectious uveitis requires treatment of the underlying infectious pathogen, whereas treatment of non-infectious uveitis $(\mathrm{NIU})$ is directed at controlling ocular inflammation. Anterior uveitis is typically managed with topical corticosteroids; however, treatment of posterior uveitis usually requires local and/or systemic therapy due to the limited penetration of topical agents into the posterior segment. ${ }^{1,2}$ Systemic corticosteroids are often prescribed as the initial treatment for NIU of the posterior segment (NIU-PS), but long-term use is associated with significant adverse effects that generally preclude prolonged administration., ${ }^{2,4}$

The treatment-limiting adverse effects of conventional therapies coupled with emerging insights into the pathogenesis of NIU have led to the development of novel, targeted therapeutic interventions for NIU-PS. Such interventions include agents aimed at a specific molecular pathway as well as therapies that utilize targeted delivery systems to achieve high therapeutic concentrations at the site of inflammation, and thereby minimize systemic exposure. Currently available therapies, including both targeted and non-specific agents, have been extensively reviewed elsewhere. ${ }^{2,4-7}$ This article provides an overview of novel emerging targeted therapies that are currently under clinical investigation for the treatment of NIU-PS.

\section{Systemic therapies}

Evidence from experimental models of uveitis suggests that proinflammatory cytokines such as interleukin (IL)-6 and IL-23 promote the activation and clonal expansion of T helper $\left(T_{H}\right)$ cells, particularly $T_{H} 17$ cells, which weaken the blood-retinal barrier and allow leukocytes to enter and damage ocular tissues (Figure 1). ${ }^{8-10}$ Studies in patients with uveitis have shown elevated levels of IL-6, IL-10, IL-17, IL-22, IL-23, and tumor necrosis factor alpha (TNF $\alpha$ ), supporting the hypothesis that $T_{H}$ 17-effector cytokines are central mediators of ocular inflammation and thus potential therapeutic targets. ${ }^{11}$ These and other observations have led to the investigation of several systemic agents that target key mediators of inflammatory pathways for the treatment of NIU-PS (Table 1).

\section{Sarilumab}

Sarilumab (Kevzara ${ }^{\circledR}$; Sanofi, Paris, France) is a human monoclonal antibody that binds to the IL-6 receptor and inhibits IL-6-mediated signaling.12,13 Sarilumab is currently approved for the 


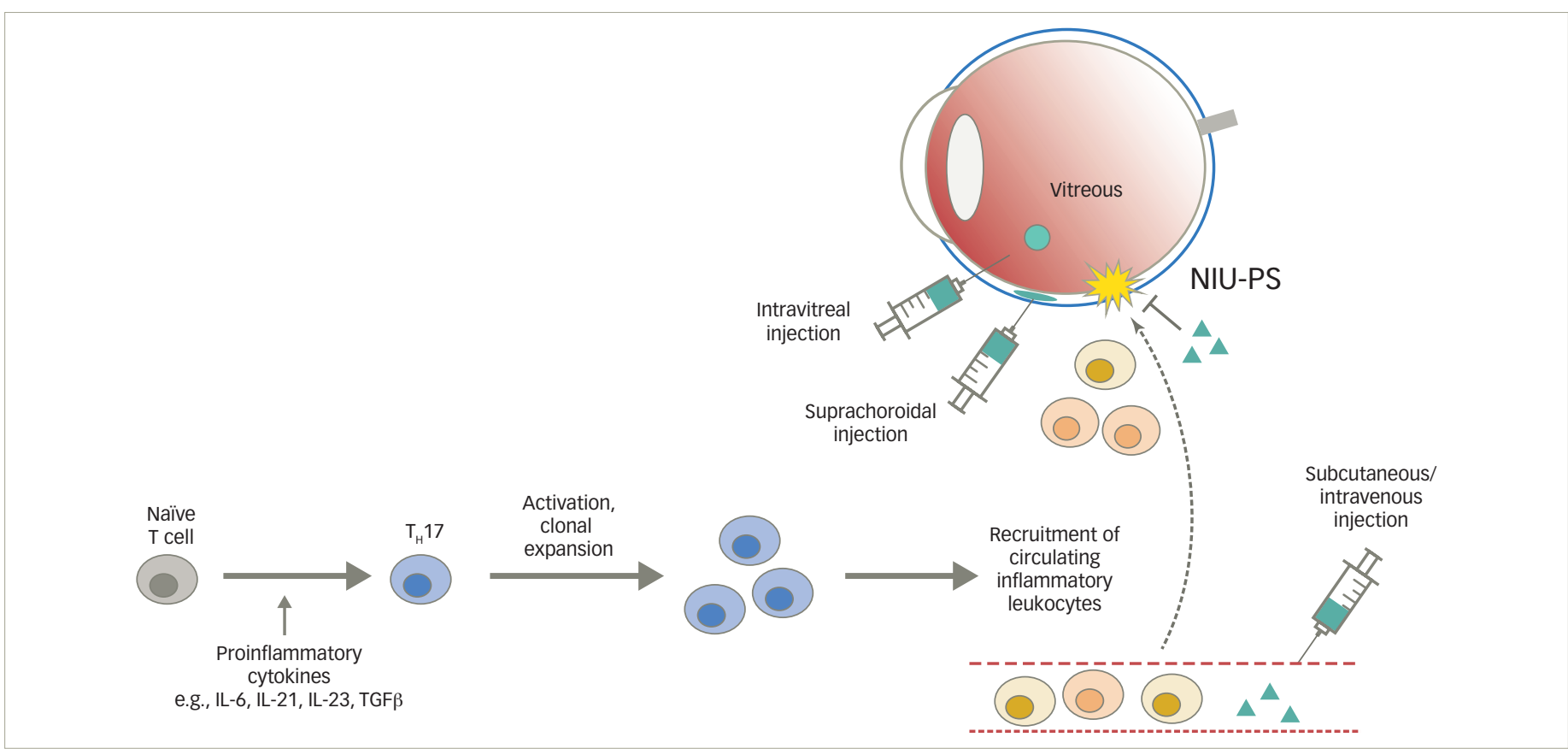

Animal models of uveitis and studies in patients with NIU-PS suggest that proinflammatory cytokines play a critical role in the differentiation of naive T cells (gray) into TH17 cells (blue), which subsequently recruit circulating inflammatory leukocytes (gold and orange) into the eye. ${ }^{10}$ Several local and systemic corticosteroid-sparing agents (green) are under development as potential therapies for NIU-PS. Intravitreal and suprachoroidal injections are two methods of intraocular drug delivery that allow sustained release of therapeutic concentrations of drugs targeting ocular inflammation in the posterior segment from either within the vitreous or from the suprachoroidal space (light blue), a naturally occurring space between the choroid and the sclera.

IL = interleukin; NIU-PS = non-infectious uveitis of the posterior segment; TGF = transforming growth factor; $T H=T$ helper.

Table 1: Investigational systemic therapies for non-infectious uveitis of the posterior segment

\begin{tabular}{|c|c|c|c|}
\hline Therapy & Target/mechanism of action & Dosage & Status \\
\hline $\begin{array}{l}\text { Filgotinib } \\
\text { (Gilead Sciences, Inc., Foster City, CA, US) }\end{array}$ & JAK 1 inhibition & 200 mg daily, orally & $\begin{array}{l}\text { Phase II trial initiated July 2016; } \\
\text { results expected July } 2022\end{array}$ \\
\hline $\begin{array}{l}\text { Repository corticotropin injection } \\
\text { (Mallinckrodt Pharmaceuticals, Hampton, NJ, US) }\end{array}$ & ACTH analogue & $\begin{array}{l}80 \text { U subcutaneously two or } \\
\text { three times weekly }\end{array}$ & $\begin{array}{l}\text { Phase II trial initiated January 2017; } \\
\text { results expected December } 2019\end{array}$ \\
\hline $\begin{array}{l}\text { Sarilumab } \\
\text { (Sanofi SA, Paris, France) }\end{array}$ & IL-6 inhibition & 200 mg subcutaneously every 2 weeks & Phase II trial completed April 2016 \\
\hline $\begin{array}{l}\text { Tocilizumab } \\
\text { (Genentech, Inc., San Francisco, CA, US) }\end{array}$ & IL-6 inhibition & 4 or 8 mg/kg monthly & Phase I/II trial completed December 2017 \\
\hline $\begin{array}{l}\text { Ustekinumab } \\
\text { (Janssen Biotech, Inc., Horsham, PA, US) }\end{array}$ & IL-12, IL-23 inhibition & 90 mg every 2 weeks & $\begin{array}{l}\text { Phase II pilot study initiated September } \\
\text { 2016; results expected December } 2018\end{array}$ \\
\hline
\end{tabular}

$A C T H=$ adrenocorticotropic hormone; $I L=$ interleukin; JAK = Janus kinase.

treatment of rheumatoid arthritis. ${ }^{12}$ Animal studies have shown that IL-6-deficient mice are partially protected against induction of experimental autoimmune uveitis, and systemic administration of an anti-IL-6 antibody to mice attenuates experimental autoimmune uveitis. ${ }^{14}$ The clinical efficacy of sarilumab in patients with NIU-PS was recently evaluated in Phase ॥ Study to Analyze Sarilumab in Non-infectious Uveitis (SARILNIUSATURN; ClinicalTrials.gov identifier: NCT01900431), a multinational, phase ॥, randomized, double-masked, placebo-controlled trial. A total of 58 patients received either subcutaneous sarilumab $200 \mathrm{mg}$ or placebo every 2 weeks for 52 weeks. Preliminary results showed no statistically significant difference in the proportion of patients achieving a $\geq 2$-step reduction in vitreous haze $(\mathrm{VH})$ score at week 16 , as assessed by a reading center, or a prednisone dose of $<10 \mathrm{mg} /$ day (primary endpoint), but suggested a potential benefit in reducing uveitic macular edema. ${ }^{15}$ Ocular serious adverse events occurred in one patient (2.6\%) in the sarilumab group (uveitis) and one (5.0\%) in the placebo group (increased intraocular pressure [IOP]). Final published results from the SARILNIUSATURN study are not yet available.

\section{Tocilizumab}

Tocilizumab (Actemra ${ }^{\circledR}$; Genentech, San Francisco, CA, US), a humanized monoclonal antibody against the IL-6 receptor, is approved for the treatment of rheumatoid arthritis, juvenile idiopathic arthritis, giant cell arteritis, and cytokine release syndrome. ${ }^{16}$ The effect of tocilizumab in patients with NIU was evaluated in a phase I/II, open-label, randomized 
clinical trial, Study of the Safety, Tolerability, and Bioactivity of Tocilizumab On Patients With Non-infectious UVEITIS: The STOP-UVEITIS Study (STOP-Uveitis; ClinicalTrials.gov identifier: NCT01717170). ${ }^{17} \mathrm{~A}$ total of 37 patients received intravenous infusions of tocilizumab (4 or $8 \mathrm{mg} / \mathrm{kg}$ ) every 4 weeks for 6 months. The primary outcome was the incidence and severity of systemic and ocular adverse events at month 6. Adverse events were generally consistent with observations from prior studies. ${ }^{10}$ Two patients in the $8 \mathrm{mg} / \mathrm{kg}$ dose group experienced neutropenia after the first dose of tocilizumab, one of whom discontinued study treatment. The most common ocular adverse event was increased IOP, which occurred in three eyes. One patient in each dose group received rescue therapy due to worsening inflammation. Analysis of efficacy outcomes at month 6 showed improvements in best corrected visual acuity (BCVA; mean change: +10.9 letters [4 mg/kg] and +5.5 letters [8 $\mathrm{mg} / \mathrm{kg}$ ]), VH score (mean change: -0.63 [4 $\mathrm{mg} / \mathrm{kg}$ ] and -0.91 [8 $\mathrm{mg} / \mathrm{kg}$ ]), and central macular thickness (mean change: -131.5 mm [4 mg/kg] and $-38.92 \mathrm{~mm}[8 \mathrm{mg} / \mathrm{kg}]$ ). Additionally, tocilizumab appeared to have a corticosteroid-sparing effect, with all but one of the seven patients who required systemic corticosteroids at baseline discontinuing treatment by month 6 . Based on the findings, the authors concluded that further evaluation of tocilizumab in patients with NIU-PS is warranted. ${ }^{17}$ Notably, a recent prospective observational cohort study based on data from the British Society for Rheumatology Biologics Register found that tocilizumab was associated with a higher risk of serious infection compared with other biologic therapies in patients with rheumatoid arthritis. ${ }^{18}$

\section{Ustekinumab}

Ustekinumab (Stelara ${ }^{\circledR}$; Janssen Biotech, Inc., Horsham, PA, US) is a human monoclonal antibody that binds to the p40 subunit of both IL-12 and IL-23, thereby disrupting IL-12- and IL-23-mediated signaling. ${ }^{19,20}$ Ustekinumab is approved for the treatment of plaque psoriasis, psoriatic arthritis, and Crohn's disease. A small, non-randomized, uncontrolled, open-label pilot study (ClinicalTrials.gov identifier: NCT02911116) evaluating ustekinumab in patients with NIU-PS was initiated in September 2016. Up to seven patients will receive subcutaneous injections of ustekinumab $90 \mathrm{mg}$ at baseline and at weeks 2 and 4 . Preliminary results for the first four patients enrolled in the study were presented at the 2018 annual meeting of the Association for Research in Vision and Ophthalmology (ARVO). ${ }^{21}$ Early analyses showed evidence of benefit in three patients with no significant adverse events reported during 28 weeks of follow up. The study is ongoing and is expected to be completed in December 2018.

\section{Filgotinib}

Filgotinib (Gilead Sciences, Inc., Foster City, CA, US) is an oral Janus kinase 1 (JAK1) inhibitor that is currently in phase III development for the treatment of rheumatoid arthritis and inflammatory bowel disease.22,23 IL-6, a proinflammatory cytokine involved in the pathogenesis of NIU-PS, ${ }^{11}$ acts through a JAK1-mediated signaling pathway, ${ }^{24}$ suggesting a potential therapeutic role for JAK1 inhibition in NIU-PS. Based on this evidence, a multicenter, phase II, double-masked, randomized, placebo-controlled trial (ClinicalTrials.gov identifier: NCT03207815) is currently under way to evaluate the safety and efficacy of filgotinib in patients with active NIU. Patients will receive $200 \mathrm{mg}$ oral filgotinib once daily, or placebo, for up to 52 weeks. The primary outcome measure will evaluate the proportion of patients meeting at least one of the pre-defined criteria for treatment failure at week 24 based on assessments of BCVA, VH, anterior chamber cell grade, and inflammatory lesions. The study is expected to be completed in July 2022.

\section{Repository corticotropin injection}

Repository corticotropin injection (Acthar $^{\circledR}$ gel; Mallinckrodt Pharmaceuticals, Hampton, NJ, US) is an adrenocorticotropic hormone analogue with anti-inflammatory effects. It is currently used to treat a wide range of inflammatory and autoimmune diseases, including diffuse posterior uveitis. ${ }^{25-27}$ A phase II, open-label, randomized clinical trial (ClinicalTrials.gov identifier: NCT02931175) evaluating the bioactivity and safety of repository corticotropin injection in patients with NIU was initiated in January 2017. Patients will receive treatment with repository corticotropin $80 \mathrm{U} /$ day, administered subcutaneously either two or three times per week for up to 12 months. The primary outcome measures include the incidence of ocular and systemic adverse events at 6 and 12 months.

\section{Intraocular drug delivery}

Targeted delivery of therapeutic agents via intraocular administration yields high therapeutic concentrations at the site of inflammation with potentially lower systemic exposure than oral or intravenous administration. Current routes of intraocular drug delivery include intravitreal injections and corticosteroid implants. Suprachoroidal injections, which utilize the naturally occurring suprachoroidal space between the sclera and choroid as a therapeutic reservoir, represent another potential option.,28 The following section provides an overview of emerging local therapies for patients with NIU-PS (Table 2). ${ }^{45}$

\section{Corticosteroid implants}

Intravitreal corticosteroid injections have been shown to improve visual acuity and reduce inflammation in patients with NIU-PS; however, repeated injections are necessary to maintain the effect. ${ }^{29,30}$ Repeated intravitreal injections are generally well tolerated, but have been associated with transient increases in IOP post-injection, cataract formation, endophthalmitis, and retinal detachment.,29,30 Corticosteroid implants are designed to provide local sustained release of drug over periods ranging from 6 months to 3 years, thereby reducing the need for repeat administration. 2,5 Two sustained-release corticosteroid implants are currently approved for the treatment of NIU-PS (Retisert ${ }^{\circledR}$; Bausch + Lomb, Bridgewater, NJ, US; Ozurdex ${ }^{\circledR}$; Allergan, Inc., Irvine, CA, US) and two additional corticosteroid implants are in late-stage clinical development for the treatment of NIU-PS (YUTIQ ${ }^{\text {TM }}$; EyePoint Pharmaceuticals, Inc., Watertown, MA, US; Iluvien $^{\circledR}$; Alimera Sciences, Inc., Alpharetta, GA, US).

YUTIQ is an injectable intravitreal micro-implant containing $0.18 \mathrm{mg}$ of fluocinolone acetonide that provides sustained drug delivery for up to 3 years. In contrast to the surgically implanted $0.59 \mathrm{mg}$ fluocinolone device (Retisert), it is implanted via an injection that can be administered in the office setting. ${ }^{31}$ Two recent phase III, multicenter, randomized, placebo-controlled trials evaluated the efficacy and safety of the fluocinolone acetonide $0.18 \mathrm{mg}$ micro-implant in patients with NIU-PS (ClinicalTrials.gov identifiers: NCT01694186 and NCT02746991). Published results are not yet available; however, pooled 6-month results from the two trials $(\mathrm{N}=282)$ presented at the 2018 ARVO meeting showed improvements in the rate of uveitis recurrence (26.6\% versus $73.4 \% ; p<0.001)$ and visual acuity (mean change: +6.0 versus +4.4 letters) in implanted eyes compared with sham-treated eyes. ${ }^{32}$ However, IOP elevation of $\geq 12 \mathrm{mmHg}$ was more common in implanted eyes compared with sham controls (12.2\% versus $4.3 \%$ ). Based on the results of the phase III trials, a New Drug Application was submitted to the US Food and Drug Administration in January 2018. ${ }^{33}$ 
Table 2: Investigational local therapeutic agents for non-infectious uveitis of the posterior segment

\begin{tabular}{|c|c|c|c|}
\hline Therapy & Mechanism of action & Dosage & Status \\
\hline $\begin{array}{l}\text { Fluocinolone acetonide intravitreal implant } \\
\text { (Alimera Sciences, Inc., Alpharetta, GA, US) }\end{array}$ & Glucocorticoid receptor agonist & $\begin{array}{l}0.19 \mathrm{mg} \text { sustained release } \\
\text { ( } \sim 3 \text { years) }\end{array}$ & $\begin{array}{l}\text { Application for NIU-PS indication filed in } \\
\text { January } 2018^{*}\end{array}$ \\
\hline $\begin{array}{l}\text { Fluocinolone acetonide intravitreal implant } \\
\text { (EyePoint Pharmaceuticals, Inc., Watertown, MA, US) }\end{array}$ & Glucocorticoid receptor agonist & $\begin{array}{l}0.18 \mathrm{mg} \text { sustained release } \\
\text { ( 3 years) }\end{array}$ & $\begin{array}{l}\text { Phase III trial completed } \\
\text { April } 2017\end{array}$ \\
\hline $\begin{array}{l}\text { Suprachoroidal triamcinolone acetonide } \\
\text { (Clearside Biomedical, Inc., Alpharetta, GA, US) }\end{array}$ & Glucocorticoid receptor agonist & $4 \mathrm{mg}^{+}$ & Phase III trials completed January 2018 \\
\hline $\begin{array}{l}\text { Intravitreal sirolimus } \\
\text { (Santen Inc., Emeryville, CA, US) }\end{array}$ & mTOR inhibitor & $\begin{array}{l}\text { 44, } 440, \text { or } 880 \mu g \\
\text { bimonthly }^{* *}\end{array}$ & $\begin{array}{l}\text { Two phase III trials completed December 2016; } \\
\text { third phase III trial in } 2018\end{array}$ \\
\hline $\begin{array}{l}\text { Intravitreal infliximab } \\
\text { (Janssen Biotech, Horsham, PA, US) }\end{array}$ & TNF $\alpha$ inhibitor & $1.5 \mathrm{mg}$ & No active clinical trials in NIU-PS \\
\hline $\begin{array}{l}\text { Intravitreal ranibizumab } \\
\text { (Genentech, Inc. South San Francisco, CA, US) }\end{array}$ & VEGF inhibitor & $0.5 \mathrm{mg} \ddagger$ & Phase III trial initiated January 2017 \\
\hline $\begin{array}{l}\text { Intravitreal methotrexate } \\
\text { (generic) }\end{array}$ & $\begin{array}{l}\text { Adenosine-mediated } \\
\text { leukocyte inhibition }\end{array}$ & $400 \mu g$ & Phase III trial initiated January 2017 \\
\hline $\begin{array}{l}\text { Tesidolumab/LFG316 } \\
\text { (Novartis Pharmaceuticals, Basel, Switzerland) }\end{array}$ & C5 inhibitor & NR & Phase II trial completed December 2017 \\
\hline $\begin{array}{l}\text { pEYS606 gene therapy } \\
\text { (Eyevensys SAS, Paris, France) }\end{array}$ & Inhibition of TNF $\alpha$ expression & NR & Phase I/II trial initiated April 2017 \\
\hline \multicolumn{4}{|c|}{ 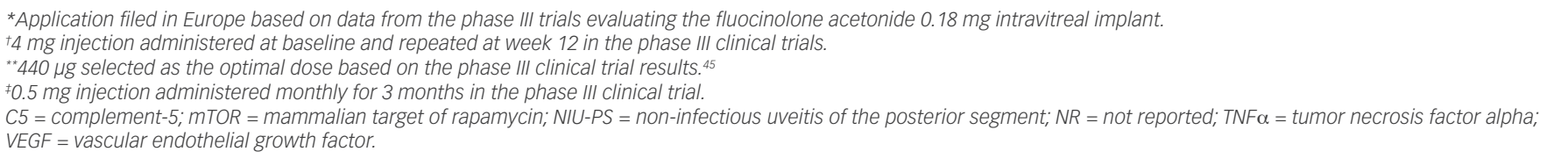 } \\
\hline
\end{tabular}

Iluvien is a non-biodegradable, injectable intravitreal device that uses the same delivery platform as the YUTIQ micro-implant, providing sustained release of $0.19 \mathrm{mg}$ fluocinolone acetonide for up to 3 years. ${ }^{34}$ It is currently approved in the United States and Europe for the treatment of diabetic macular edema. ${ }^{34,35}$ Pooled data from two randomized, double-masked, sham-controlled studies in patients with diabetic macular edema showed that Iluvien was generally safe and well tolerated. ${ }^{36}$ Cataract surgery was the most common drug-related serious adverse event, occurring in $41.1 \%$ and $7.0 \%$ of study eyes in the lluvien and control groups, respectively. In accordance with a licensing and data sharing agreement with EyePoint Pharmaceuticals, an application seeking an expanded indication for the treatment of NIU-PS was filed in Europe in December 2017 based on the results of the two phase III trials evaluating the YUTIQ $0.18 \mathrm{mg}$ fluocinolone implant. ${ }^{37,38}$

\section{Suprachoroidal injection}

Targeted delivery of therapeutic agents to the suprachoroidal space offers the potential advantage of high sustained drug concentrations in the choroid and retina with minimal exposure in other areas of the eye..$^{28}$ Two recent trials (Suprachoroidal Injection of CLS-TA in Subjects With Macular Edema Associated With Non-infectious Uveitis [PEACHTREE], ClinicalTrials.gov identifer: NCT02595398; Suprachoroidal Injection of CLS-TA in Subjects Non-infectious Uveitis [AZALEA], Clinicaltrials. gov identifier: NCT03097315) investigated the safety and efficacy of $4 \mathrm{mg}$ triamcinolone acetonide administered via suprachoroidal injection using a proprietary injection device (Clearside Biomedical, Alpharetta, GA, US) in patients with NIU (anterior, intermediate, posterior, and panuveitis). PEACHTREE was a phase III, quadruple-masked, sham-controlled trial in 160 patients with macular edema associated with NIU; AZALEA was an open-label safety study in 38 patients with NIU. The trials were completed in January 2018. At the time of writing, published study results were not available; however, in a press release issued in March 2018, the study sponsor announced that the primary endpoint was successfully met in the PEACHTREE trial: $\geq 15$ letter improvement in BCVA at week 24 was observed in $46.9 \%$ of patients receiving $4 \mathrm{mg}$ suprachoroidal triamcinolone acetonide every 12 weeks and $15.6 \%$ in the sham-control group $(p<0.001) .{ }^{39}$ Administration of suprachoroidal triamcinolone acetonide resulted in a mean reduction from baseline of 157 microns in central subfield thickness at week 24 versus 19 microns in the sham arm $(p<0.001) .39,40$ Treatment was generally well tolerated, although IOP-related adverse events were more common in patients treated with suprachoroidal triamcinolone compared with sham controls (11.5\% versus $0 \%$, respectively).

\section{Intravitreal sirolimus}

Sirolimus is an immunomodulatory agent that inhibits the mammalian target of rapamycin (mTOR), a protein kinase involved in the regulation of T-cell activation, proliferation, and differentiation, and proinflammatory cytokine production. ${ }^{41,42}$ Oral sirolimus is currently approved for the prevention of organ rejection following renal transplant and the treatment of Iymphangioleiomyomatosis. ${ }^{43}$ A novel intravitreal formulation that delivers therapeutic concentrations to the eye with minimal systemic exposure has been developed by Santen Inc. (Emeryville, CA, US) and evaluated in clinical trials for the treatment of NIU-PS. ${ }^{44}$ The Study Assessing Double-masked Uveitis Treatment (SAKURA; ClinicalTrials.gov identifer: NCT01358266) comprised two sequential phase III, multinational, randomized, double-masked studies assessing the efficacy and safety of intravitreal sirolimus in patients with active NIU-PS. 
In SAKURA 1,347 patients were randomly assigned to receive one of three doses of intravitreal sirolimus (44, 440, and $880 \mathrm{mg}$ ) administered on days 1,60 , and $120 .{ }^{45} \mathrm{~A}$ significantly higher proportion of patients in the $440 \mathrm{mg}$ dose group achieved the primary endpoint of a VH score of 0 at month 5 compared with the $44 \mathrm{mg}$ dose group (22.8\% versus $10.3 \%$; $p=0.025)$. Likewise, the proportion of patients achieving the secondary endpoint of a $\mathrm{VH}$ score of 0 or $0.5+$ was significantly higher in the $440 \mathrm{mg}$ group compared with the $44 \mathrm{mg}$ group (52.6\% versus 35\%; $\mathrm{p}=0.008$ ). Comparison between the $880 \mathrm{mg}$ and $44 \mathrm{mg}$ dose groups showed no significant difference in the proportion of patients achieving a VH score of 0 (16.4\% versus $10.3 \%$; $p=0.182$ ). BCVA improved or was maintained in $80 \%$ of patients in all dose groups. Logistic regression analysis showed a higher likelihood of improvement in BCVA in patients in the $440 \mathrm{mg}$ group who had low BCVA at baseline; median improvement was +10.5 letters in patients with baseline BCVA of $<20 / 100 \quad(n=46)$ versus 1.0 letter in those with baseline BCVA of $\geq 20 / 40 \quad(n=149)$. All three doses appeared to have a corticosteroid-sparing effect; $69.6 \%$ of patients who required systemic corticosteroids at baseline were able to taper the dosage to $\leq 5 \mathrm{mg} /$ day (prednisone equivalent) by month 5 . Treatment with intravitreal sirolimus was generally well tolerated. There were no clinically significant changes in mean IOP and treatment-related ocular serious adverse events were uncommon in all three groups. ${ }^{45}$

Collectively, the efficacy and safety results from the first trial suggested that the $440 \mathrm{mg}$ dose offered the most favorable benefit/risk profile in the treatment of NIU-PS. Based on this finding, the protocol for the second trial was amended to terminate further investigation of the $880 \mathrm{mg}$ dose. The primary endpoint ( $\mathrm{VH}=0$ at month 5 response) in the $440 \mathrm{mg}$ group in SAKURA 2 was consistent with what was reported in the first trial, but the difference did not reach statistical significance when compared with the $44 \mathrm{mg}$ group (19.1\% versus 17.6\%; $p=0.783) .{ }^{46}$ Santen Inc. is planning a new phase III trial evaluating intravitreal sirolimus in patients with NIU-PS.

\section{Intravitreal infliximab}

Infliximab (Remicade ${ }^{\circledR}$; Janssen Biotech, Horsham, PA, US) is a chimeric monoclonal antibody to TNF $\alpha$ that is currently approved for the treatment of a variety of inflammatory and autoimmune conditions. ${ }^{47}$ Systemic administration of infliximab is associated with toxicities such as heart failure, exacerbation of multiple sclerosis, and tuberculosis reactivation; however, targeted delivery of infliximab via intravitreal injection results in increased local concentrations with reduced systemic exposure.48 In a prospective case series including 10 eyes from seven patients with chronic NIU, intravitreal injection of infliximab $1.5 \mathrm{mg}$ improved mean BCVA, VH score, and central macular thickness at 4 weeks. ${ }^{49}$ Subsequent analysis of long-term outcomes in the same cohort showed that the benefit was transient; mean BCVA, VH score, and central macular thickness returned to pre-treatment values by month 6. No significant ocular or systemic complications were reported in this series. ${ }^{48}$ At the time of writing, there were no active clinical trials evaluating intravitreal infliximab in patients with NIU-PS.

\section{Intravitreal ranibizumab}

Ranibizumab (Lucentis ${ }^{\circledR}$; Genentech, San Francisco, CA, US) is a monoclonal antibody that inhibits the biologic activity of vascular endothelial growth factor A. ${ }^{50}$ Intravitreal ranibizumab is currently indicated for the treatment of neovascular age-related macular degeneration, retinal vein occlusion, diabetic macular edema, diabetic retinopathy, and myopic choroidal neovascularization..$^{50}$ In a prospective case series of seven patients with uveitis and refractory central macular edema, intravitreal ranibizumab $(0.5 \mathrm{mg})$ administered monthly for 3 months resulted in significant improvements in BCVA (mean change: +13 letters; $p=0.03$ ) and central retinal thickness (mean change: $-357 \mu \mathrm{m} ; \mathrm{p}=0.03$ ) at 3 months compared with baseline. ${ }^{51}$ Most patients required reinjection after 3 months; however, the improvements in BCVA and central retina thickness were maintained at 6 months. Treatment was generally well tolerated, with no evidence of significant ocular or systemic adverse effects. A phase III, randomized comparative trial (Macular Edema Ranibizumab v. Intravitreal Anti-inflammatory Therapy Trial [MERIT], ClinicalTrials.gov identifier: NCT02623426) evaluating treatment with either intravitreal ranibizumab, intravitreal methotrexate, or a dexamethasone implant in 240 patients with NIU-associated macular edema is currently underway and expected to be completed in July 2019.

\section{Intravitreal methotrexate}

Methotrexate is a cytotoxic agent that exhibits dose-dependent inhibitory effects on neutrophils, macrophages, and T-cells. ${ }^{52-55} \mathrm{~A}$ pilot study evaluating intravitreal methotrexate $(400 \mu \mathrm{g})$ in 15 patients with NIU showed statistically significant improvements in visual acuity, VH score, and macular thickness compared with baseline. ${ }^{56}$ Five of 13 patients who responded to treatment relapsed after a median duration of 4 months; all four patients who received a repeat injection experienced improved visual acuity following reinjection. Mild ocular pain was the only injection-related adverse event and no patient experienced increased IOP. In a subsequent retrospective case series of 30 patients with NIU, 79\% of treated eyes showed improvement in BCVA, ocular inflammation, or central macular thickness over assessment intervals of varying duration. ${ }^{57}$ Eight of 30 eyes that responded to initial treatment relapsed (median time to relapse, 3 months); of these eyes, all 8 responded to repeat injection. The median duration of remission in the remaining 22 eyes was 17 months. Eight of 14 patients (57\%) who were receiving concomitant therapy with systemic corticosteroids were able to reduce the dose following treatment with intravitreal methotrexate. Treatment appeared to be generally well tolerated; however, adverse events were not prospectively assessed. As noted above, a randomized trial comparing intravitreal methotrexate with either intravitreal ranibizumab or a corticosteroid implant in patients with uveitic macular edema is ongoing.

\section{Intravitreal tesidolumab/LFG316}

Tesidolumab/LFG316 (Novartis Pharmaceuticals; Basel, Switzerland) is a monoclonal antibody against the complement 5 protein. ${ }^{58} \mathrm{~A}$ recent phase II, multicenter, randomized, controlled, open-label study (ClinicalTrials.gov identifer: NCT01526889) evaluated the safety, efficacy, and pharmacokinetics of intravitreal tesidolumab/LFG316 in patients with active NIU-PS. Patients were randomized to treatment with tesidolumab/LFG316 or conventional immunosuppressive therapy for 12 weeks; patients who met the criteria for treatment response at week 12 were permitted to continue study treatment for an additional 6 months. The study was completed in December 2017; however, published results are not yet available. 


\section{pEYS606 gene therapy}

pEYS606 (Eyevensys SAS; Paris, France) is a DNA plasmid that encodes for a fusion protein of the TNF $\alpha$ receptor and immunoglobulin G. ${ }^{59}$ The pEYS606 plasmid solution is administered by electrotransfection into the ciliary muscle cells using a proprietary disposable electroporation device. Ciliary muscle cells exhibit high transfection efficiency and subsequent protein synthesis in various animal models, and preclinical studies have shown pEYS606 to be efficacious in animal models of

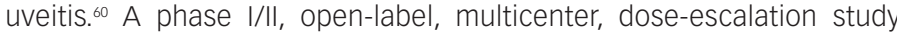
evaluating the safety, tolerability, and clinical activity of pEYS606 in 24 patients with NIU-PS (ClinicalTrials.gov identifer: NCT03308045) is currently underway in the UK and France, and is expected to be completed in December 2019

\section{Conclusion}

The primary goals of therapy in patients with chronic NIU-PS are to achieve durable control of ocular inflammation and prevent sight-threatening complications. ${ }^{1,2}$ Treatment-limiting systemic adverse effects associated with conventional therapies have prompted the development of therapies that allow targeted local delivery of drugs to the site of inflammation, while insights regarding the pathogenesis of NIU have led to the emergence of therapies that target specific mediators of autoinflammatory pathways. The expanding range of targeted therapeutic options in development for the management of NIU is promising and will serve to enhance the ability to tailor therapy according to individual patient circumstances, while offering the potential for improved outcomes with reduced systemic exposure to corticosteroids.
1. Krishna U Aianaku D, Denniston AK, Gkika T Uveitis: a sight-threatening disease which can impact all systems. Postgrad Med J. 2017;93:766-73.

2. Tan HY, Agarwal A, Lee CS, et al. Management of noninfectious posterior uveitis with intravitreal drug therapy. Clin Ophthalmol. 2016;10:1983-2020.

3. Nguyen QD, Callanan D, Dugel P, et al. Treating chronic noninfectious posterior segment uveitis: the impact of cumulative damage. Proceedings of an expert panel roundtable discussion. Retina. 2006;Oct Suppl:1-16.

4. Pasadhika S, Rosenbaum JT. Update on the use of systemic biologic agents in the treatment of noninfectious uveitis. Biologics. 2014;8:67-81.

5. Lee DJ. Intraocular implants for the treatment of autoimmune uveitis. J Funct Biomater. 2015;6:650-66.

6. Brady CJ, Villanti AC, Law HA, et al. Corticosteroid implants for chronic non-infectious uveitis. Cochrane Database Syst Rev. 2016;2:CD010469.

7. Sharma MS, Fu DJ, Xin K. A review of the landscape of targeted immunomodulatory therapies for non-infectious uveitis. Ophthalmol Ther. 2018;7:1-17.

8. Lipski DA, Dewispelaere R, Foucart V, et al. MHC class II expression and potential antigen-presenting cells in the retina during experimental autoimmune uveitis. J Neuroinflamm. 2017;14:136

9. Guedes MCE, Borrego LM, Proença RD. Roles of interleukin-17 in uveitis. Indian J Ophthalmol. 2016;64:628-34.

10. Caspi RR. A look at autoimmunity and inflammation in the eye J Clin Invest. 2010;120:3073-83.

11. Weinstein JE, Pepple KL. Cytokines in uveitis. Curr Opin Ophthalmol. 2018;29:267-74.

12. KEVZARA ${ }^{\oplus}$ (sarilumab) [Package insert]. Bridgewater, $\mathrm{NJ}$ : Sanofi-Aventis U.S. LLC; 2017.

13. Lee EB. A review of sarilumab for the treatment of rheumatoid arthritis. Immunotherapy. 2018;10:57-65.

14. Yoshimura T, Sonoda KH, Ohguro N, et al. Involvement of Th17 cells and the effect of anti-lL-6 therapy in autoimmune uveitis. Rheumatology (Oxford). 2009;48:347-54.

15. Nguyen QD, Heissigerova J, Varona R, et al. Sarilumab in the management of posterior segment noninfectious uveitis: the SATURN study. Presented at: the 2017 American Academy of Ophthalmology Annual Meeting, New Orleans, LA, US, November 11-14, 2017.

16. ACTEMRA ${ }^{\oplus}$ (tocilizumab) [Package insert]. South San Francisco, CA: Genentech, Inc:; 2017.

17. Sepah YJ, Sadiq MA, Chu DS, et al. Primary (month-6) outcomes of the STOP-Uveitis Study: evaluating the safety, tolerability, and efficacy of tocilizumab in patients with noninfectious uveitis. Am J Ophthalmol. 2017:183:71-80.

18. Rutherford Al, Subesinghe S, Hyrich KI, Galloway JB. Serious infection across biologic-treated patients with rheumatoid arthritis: results from the British Society for Rheumatology Biologics Register for Rheumatoid Arthritis. Ann Rheum Dis. 2018;77:905-10.

19. Kotze PG, Ma C, Almutairdi A, Panaccione R. Clinical utility of ustekinumab in Crohn's disease. J Inflamm Res. 2018;11:35-47.

20. STELARA ${ }^{\otimes}$ (ustekinumab) [Package insert]. Horsham, PA: Janssen Biotech; 2016.

21. Utriainen $L$, Lee JW, Li Z, et al. Efficacy of IL-12/23 inhibition for the treatment of active sight-threatening uveitis: a pilot study. Presented at: the 2018 Association for Research in Vision and Ophthalmology (ARVO) Annual Meeting, Honolulu, HI, US, April 29-May 2, 2018.

22. Westhovens $\mathrm{R}$, Taylor PC, Alten R, et al. Filgotinib (GLPG0634/GS-6034), an oral JAK1 selective inhibitor, is effective in combination with methotrexate (MTX) in patients with active rheumatoid arthritis and insufficient response to MTX: results from a randomised, dose-finding study (DARWIN 1). Ann Rheum Dis. 2017;76:998-1008.
23. Winthrop KL The emerging safety profile of JAK inhibitors in rheumatic disease. Nat Rev Rheumatol. 2017:13:234-43.

24. Laurence A, Pesu M, Silvennoinen O, O'Shea J. JAK kinases in health and disease: an update. Open Rheumatol J. 2012;6:232-44.

25. ACTHAR ${ }^{\circledast} \mathrm{Gel}$ (repository corticotropin) [Package insert]. Union City, CA: Questcor Pharmaceuticals, Inc.: 2010.

26. Philbin M, Neiwoenher J, Wan GJ. Clinical and economic evaluation of repository corticotropin injection: a narrative literature review of treatment efficacy and healthcare resource utilization for seven key indications. Adv Ther. 2017;34:1775-90.

27. Agarwal A, Hassan M, Sepah YJ, Do DV, Nguyen QD. Subcutaneous repository corticotropin gel for non-infectious panuveitis: reappraisal of an old pharmacologic agent. Am J Ophthalmol Case Rep. 2016;4:78-82.

28. Chiang B, Jung JH, Prausnitz MR. The suprachoroidal space as route of administration to the posterior segment of the eye. $A d v$ Drug Deliv Rev. 2018:126:58-66.

29. Sallam A, Taylor SR Habot-Wilner Z et al. Repeat intravitrea triamcinolone acetonide injections in uveitic macular oedema. Acta Ophthalmologica. 2012;90:e323-5

30. Grzybowski A, Told R, Sacu S et al. 2018 update on intravitreal injections: EU retina expert consensus recommendations. Ophthalmologica. 2018:239:181-93.

31. Jaffe GJ, Lin P, Keenan RT, et al. Injectable fluocinolone acetonide long-acting implant for noninfectious intermediate uveitis, posterior uveitis, and panuveitis: two-year results. Ophthalmology. 2016;123:1940-8.

32. Suhler E. Safety and efficacy of an intravitreal $0.18 \mathrm{mg}$ fluocinolone acetonide insert (FAi) for the treatment of non-infectious posterior segment uveitis (NIPU) - pooled results of two Phase 3 trials. Presented at: the 2018 Association for Research in Vision and Ophthalmology (ARVO) Annual Meeting Honolulu HI, US, April 29-May 2, 2018.

33. EyePoint Pharmaceuticals. EyePoint Pharmaceuticals reports fiscal third quarter 2018 results [Press release], 2018. Available at: https://globenewswire.com/news-release/2018/05/08/1498919/0/ en/EyePoint-Pharmaceuticals-Reports-Fiscal-Third-Quarter-2018Results.html (accessed October 8, 2018).

34. ILUVIEN® (fluocinolone acetonide intravitreal implant) [Package insert]. Alpharetta, GA: Alimera Sciences, Inc.; 2016.

35. ILUVIEN ${ }^{\circledast}$ (fluocinolone acetonide intravitreal implant) [Summary of product characteristics]. Alpharetta, GA: Alimera Sciences, Inc.; 2016

36. Campochiaro PA, Brown DM, Pearson A, et al. Long-term benefit of sustained-delivery fluocinolone acetonide vitreous inserts for diabetic macular edema. Ophthalmology. 2011;118:626-35.

37. Alimera Sciences. Alimera Sciences receives acceptance of filing to obtain approval for ILUVIEN ${ }^{\circledR}$ non-infectious posterior uveitis indication in Europe [Press release], 2018. Available at: https:// investor.alimerasciences.com/news-releases/news-releasedetails/alimera-sciences-receives-acceptance-filing-obtainapproval (accessed May 17, 2018).

38. Eyepoint Pharmaceuticals. pSivida out-licenses EMEA rights for Durasert ${ }^{\mathrm{TM}}$ three-year treatment for posterior segment uveitis while retaining U.S. commercial rights; amended globa collaboration agreement with Alimera for ILUVIEN ${ }^{\circledast}$ improves pSivida's revenue generation. [Press release], 2017. Available at: https://globenewswire.com/news-release/2017/07/10/1042213/0/ en/pSivida-Out-licenses-EMEA-Rights-for-Durasert-Three-yearTreatment-for-Posterior-Segment-Uveitis-While-Retaining-U-STreatment-for-Posterior-Segment-Uveitis-While-Retaining-U-SCommercial-Rights-Amended-Global-Collab

39. Clearside Biomedical. Clearside Biomedical announces positive topline results from pivotal phase 3 clinical trial of CLS-TA in macular edema associated with non-infectious uveitis. [Press release], 2018. Available at: http://ir.clearsidebio.com/staticfiles/81a64805-8bd8-4dbd-bc9a-8bbbc26de070 (accessed May 2, 2018).

40. Yeh S. Suprachoroidally injected CLS-TA improves visual acuity and macular edema in noninfectious uveitis: results of the phase 3 PEACHTREE study. Presented at the American Society of Retina Specialists Annual Meeting, Vancouver BC, Canada, July 25, 2018. Available at: www.sec.gov/Archives/edgar/ data/1539029/000156459018017423/clsd-ex991_8.htm (accessed September 18, 2018)

41. Sehgal SN. Sirolimus: its discovery, biological properties, and mechanism of action. Transplant Proc. 2003:35(Suppl 3):7S-14S

42. Powell JD, Pollizzi KN, Heikamp EB, Horton MR. Regulation of immune responses by mTOR. Annu Rev Immunol. 2012;30:39-68

43. RAPAMUNE ${ }^{\oplus}$ (sirolimus) [Package insert]. New York, NY: Pfizer; 2015.

44. Mudumba S, Bezwada P, Takanaga $\mathrm{H}$, et al. Tolerability and pharmacokinetics of intravitreal sirolimus. J Ocul Pharmacol Ther 2012;28:507-14

45. Nguyen QD, Merrill PT, Clark WL, et al. Intravitreal sirolimus for noninfectious uveitis: a phase III sirolimus study assessing double-masked uveitis treatment (SAKURA). Ophthalmology. 2016;123:2413-23

46. Nguyen QD, Merrill PT, Clark L for the SAKURA Study Group. Efficacy and safety from the SAKURA Program: two phase III studies of intravitreal sirolimus every other month for noninfectious uveitis of the posterior segment. Presented at: the 2017 Annual Meeting of the Association for Research in Vision and Ophthalmology, Baltimore, MD, US, May 7-11, 2017.

47. REMICADE® (infliximab) [Package insert]. Horsham, PA: Jannsen Biotech; 2017

48. Farvardin M, Afarid M, Shahrzad S. Long-term effects of intravitreal infliximab for treatment of sight-threatening chronic noninfectious uveitis. J Ocul Pharmacol Ther. 2012;28:628-31

49. Farvardin $\mathrm{M}$, Afarid $\mathrm{M}$, Mehryar $\mathrm{M}$. Intravitreal infliximab for the treatment of sight-threatening chronic noninfectious uveitis. Retina. 2010;30:1530-5

50. LUCENTIS® (ranibizumab) [Package insert]. South San Francisco, CA: Genentech, Inc.; 2017.

51. Acharya NR, Hong KC, Lee SM. Ranibizumab for refractory uveitis-related macular edema. Am J Ophthalmol. 2009;148:303-9.

52. Cronstein BN, Naime D, Ostad E. The antiinflammatory mechanism of methotrexate. Increased adenosine release at inflamed sites diminishes leukocyte accumulation in an in vivo model of inflammation. J Clin Invest. 1993;92:2675-82.

53. Bouma MG, Stad RK, van den Windenberg FA, Buurman WA. Differential regulatory effects of adenosine on cytokine release by activated human monocytes. J Immunol. 1994;153:4159-68.

54. Constantin A, Loubet-Lescoulie P, Lambert N, et al. Antiinflammatory and immunoregulatory action of methotrexate in the treatment of rheumatoid arthritis: evidence of increased interleukin-4 and interleukin-10 expression demonstrated in vitro by competitive reverse transcriptase-polymerase chain reaction. Arthritis Rheum. 1998:41:48-57.

55. Chan ES, Cronstein BN. Molecular action of methotrexate in inflammatory diseases. Arthritis Res. 2002;4:266-73.

56. Taylor SRJ, Habot-Wilner Z, Pacheco P, Lightman SL. Intraocular methotrexate in the treatment of uveitis and uveitic cystoid macular edema. Ophthalmology. 2009;116:797-801.

57. Taylor SRJ, Banker A, Schlaen A, et al. Intraocular methotrexate can induce extended remission in some patients in noninfectious uveitis. Retina. 2013:0:1-6.

58. Roguska M, Splawski I. Diefenbach-Streiber B, et al. Generation and characterization of LFG316, a fully-human anti-C5 antibody for the treatment of age-related macular degeneration. Invest Ophthalmol Vis Sci. 2014;55:3433

59. Desort-Hénin V, Behar-Cohen F, Scorneaux B, et al. Recent advances in electroporation. Presented at: the 13th International Symposium on Ocular Pharmacology \& Therapeutics, Rome, Italy, December 1-3, 2016

60. Touchard E, Benard R, Bigot $K$, et al. Non-viral ocular gene therapy, pEYS606, for the treatment of non-infectious uveitis: preclinical evaluation of the medicinal product. J Control Release. 2018;285:244-51. 